\title{
ARQUITETURA ESCOLAR - TIPOLOGIAS ARQUITETÔNICAS DE EDIFÍCIOS DE EDUCAÇÃO FUNDAMENTAL. ESTUDO DE CASO: ESCOLA ANTÔNIO MOREIRA LIMA
}

\author{
Rafaella Rúbia do Prado Barbosa ${ }^{1}$, Yasmin Miranda Perosso ${ }^{1}$, Mayara Pissutti Albano ${ }^{1}$, Fabrícia Dias \\ da Cunha de Moraes Fernandes Borges ${ }^{1}$, Sibila de Arêa Leão Honda ${ }^{2}$ \\ ${ }^{1}$ Universidade do Oeste Paulista - UNOESTE, curso de Arquitetura e Urbanismo, Presidente Prudente, SP. ${ }^{2}$ Arquiteta \\ Urbanista, Global Planejamento. E-mail: fabricia.arquiteta@gmail.com; sibila.honda@sibila.arq.br
}

\section{RESUMO}

O presente trabalho tem como objetivo o levantamento e análises de edifícios de Ensino Fundamental I, tendo como estudo de caso a escola Antônio Moreira Lima localizada no conjunto habitacional Ana Jacinta em Presidente Prudente - SP. A metodologia adotada foi de levantamentos bibliográficos, documentais e levantamentos em campo. A importância desta pesquisa é justificada pela necessidade de espaços e estruturas adequadas às crianças de até dez anos de idade, para efetivo desenvolvimento motor, cognitivo, social e educacional. Os levantamentos visam a relacionar com a tipologia construtiva, o estilo arquitetônico e as políticas educacionais vigentes no período de implantação da referida escola.

Palavras-chave: Educação Fundamental; Edificação; Projeto de Arquitetura; Educacional; Tipologia construtiva.

\section{SCHOOL ARCHITECTURE - ARCHITECTURAL TYPOLOGY OF BUILDINGS OF BASIC EDUCATION. CASE STUDY: SCHOOL ANTÔNIO MOREIRA LIMA}

\begin{abstract}
The present work takes as an objective the lifting and analyses of buildings of Basic Teaching I, having like case study the school Antônio Moreira Files when Ana Jacinta was located in the housing set in President Prudente - SP. The adopted methodology was of bibliographical, documentary liftings and liftings in field. The importance of this inquiry is justified by the necessity of spaces and structures appropriate to the children of even ten years of age, for effective driving, cognitive, social and education development. The liftings aim to make a list with the constructive typology, the architectural style and the education policies in force in the period of introduction of the above-mentioned school.
\end{abstract}

Keywords: Basic education; Construction; Project of Architecture; Education; constructive Typology.

\section{INTRODUÇÃO}

Os edifícios Escolares, seja de educação infantil, fundamental ou ensino médio, compõem uma parcela importante dos equipamentos urbanos. Atualmente, a educação fundamental é subdividida em Fundamental I e II, sendo que crianças entre 6 anos (incompletos) e 10 anos, estão inseridas no Ensino Fundamental I, que se inicia no 10 e finaliza no 50 ano.

A provisão de escolas é de competência comum aos Estados e Municípios, conforme consta na Constituição Federal de 1988, bem como toda a estrutura necessária, as vagas e os professores, no entanto, o Estado de São Paulo municipalizou o ensino Fundamental I.

O espaço físico é um dos itens importantes para a qualidade do ensino, em especial para crianças de até 10 anos de idade, cujos edifícios, mobiliários e equipamentos necessitam ser 
adequados para tal, a fim de proporcionar condições ao desenvolvimento cognitivo, motor, social e educacional.

Há relação entre a tipologia das edificações com os equipamentos ofertados e com estilos arquitetônicos de cada período. Sendo assim, a presente pesquisa se propõe a relacionar estudos da área de Arquitetura e Urbanismo com edifícios de Ensino Fundamental I, tendo como objeto de estudo a escola Antônio Moreira Lima, localizada no conjunto habitacional Ana Jacinta, na cidade de Presidente Prudente - SP.

As cidades brasileiras apresentaram acelerado crescimento no século $X X$, intensificado a partir da década de 1960, tal fato influenciou decisivamente na estruturação das cidades e da sociedade, fazendo aumentar rapidamente a necessidade de moradia e serviços públicos, sendo a educação um dos mais relevantes, cuja oferta deve ser estabelecida através de implantação de escolas em todos os níveis de instrução. Contudo, a construção de unidades escolares e a manutenção de toda estrutura necessária possuem custos altos, dificultando a ampliação da rede de escolas de ensino público.

O Governo de Getúlio Vargas (1930-1945) torna-se um marco nas questões relativas às conquistas sociais, entre elas, a relevância dada à educação, quando a administração escolar se torna uma questão nacional, centralizando seu controle, ampliando sua rede através da abertura de novas unidades, simplificando o padrão dos edifícios, principalmente das escolas rurais, diminuindo assim os custos de construção. (SAVIANI et al, 2006; FARIA Fo. e VIDAL, 2000).

A partir de então, repetidas vezes, em diversos contextos ao longo da história, a simplicidade, a racionalização e a economia na construção dos edifícios escolares foram difundidas como manobra na promoção dos mesmos, bem como a padronização e sistematização de critérios como metodologia de projetos (AZEVEDO, BASTOS, BLOWER, 2007).

Nos dias atuais, no estado de São Paulo, a Fundação para o Desenvolvimento da Educação (FDE) é quem tem a responsabilidade de distribuir, coordenar e avaliar os projetos que são desenvolvidos por escritórios terceirizados contratados (DELIBERADOR, 2010).

Diante desse pano de fundo histórico e arquitetônico, justifica-se a importância do presente trabalho, que se propõe a analisar o projeto arquitetônico da escola de ensino fundamental de análise dos projetos de arquitetura da escola de Ensino Fundamental I - Antônio Moreira Lima.

Escolano (apud VIÑAO, 1995) afirma que o espaço institui um sistema de valores, que recobre símbolos estéticos, culturais e ideológicos; resultando em interiorização de comportamentos e de representações sociais. Dessa forma, visa-se aprofundar o conhecimento relativo à área desta pesquisa.

Assim, o objetivo geral desta pesquisa é desenvolver o levantamento projetual de edificação pública de ensino fundamental I em Presidente Prudente - SP, tendo como objeto de estudo a escola Antônio Moreira Lima, bem como relacionar seu projeto arquitetônico à época de sua construção e às políticas públicas educacionais.

A presente pesquisa compõe o projeto de pesquisa docente (EDIFÍCIOS DE EDUCAÇÃO FUNDAMENTAL EM PRESIDENTE PRUDENTE-SP - RELAÇÃO ENTRE TIPOLOGIAS ARQUITETÔNICAS, POLÍTICAS PÚBLICAS DE EDUCAÇÃO E AS TEORIAS PEDAGÓGICAS VIGENTES - protocolo 2491), que visa a analisar e identificar as edificações atuais de escola pública de ensino fundamental inseridas na malha urbana de Presidente Prudente - SP, segundo suas datas de projeto e execução, relacionando-as ao período histórico da arquitetura, ou seja, aos estilos arquitetônicos vigentes em cada momento.

\section{METODOLOGIA}

Método é a somatória de diferentes processos necessários para que o pesquisador alcance os resultados objetivos necessários. A metodologia utilizada nesta pesquisa foi desenvolvida 
através da investigação qualitativa, utilizando-se de levantamento bibliográfico, de pesquisa documental, de levantamentos físicos arquitetônicos in locu da escola supracitada, com observação sistemática da mesma.

Num primeiro momento foi realizado levantamento bibliográfico em livros e periódicos com as obras referentes às políticas educacionais brasileiras e a relação com os projetos arquitetônicos dos edifícios escolares. Numa segunda fase, foram desenvolvidas pesquisas documentais para verificação da data do projeto e de execução do edifício escolar através dos documentos existentes na própria escola, cujo acesso foi previamente autorizado pela Secretaria Municipal de Educação, através dos documentos e autorizações concedidas para o PPD no qual o presente projeto de iniciação científica está vinculado, citado anteriormente.

Posteriormente foram realizados levantamentos in locu, previamente autorizados com medições do edifício para o desenvolvimento das peças gráficas de projeto arquitetônico (plantas, cortes e fachadas) que foram representadas com o auxílio do software AutoCad. Após a conclusão das fases iniciais foram desenvolvidas análises comparativas sistemáticas através da observação intensiva, visando analisar se o projeto da escola estudada se encontra em conformidade ou desconformidade com as diretrizes projetuais apresentadas pela Fundação para o Desenvolvimento da Educação - FDE da Secretaria de Educação do Estado de São Paulo.

\section{BREVE ESTUDO DOS EDIFÍCIOS ESCOLARES NO BRASIL}

A educação tem papel essencial na formação da sociedade, difundida pelo próprio homem, de geração em geração, é fortalecida através das instituições de ensino (KOWALTOWSKI, 2011). De acordo com a Fundação para o Desenvolvimento da Educação - FDE (apud, AZEVEDO, 2002, p. 9) "o prédio escolar, além de abrigar fisicamente seus usuários, constitui condição básica para o desenvolvimento das atividades educacionais no seu interior e, portanto, suporte e material de ensino e aprendizagem".

Primordialmente o processo de educação não se dava em escolas e sim em espaços abertos ou em lugares que já possuíam outra finalidade, como residências, hotéis ou igrejas, lugares estes que não apresentavam os requisitos para um bom ensino, foi somente a partir do século $V$ que surgiram as primeiras escolas, ou seja, as primeiras edificações destinadas exclusivamente a este fim (NASCIMENTO, 2012).

Ainda de acordo com Nascimento (2012), surgia assim um gradativo procedimento para se estabelecer uma tipologia escolar fundamentada nas edificações que anteriormente a acolheram, contudo a partir deste momento as escolas ganhavam ambientes específicos, ambientes estes "[...] que despertasse o interesse e criasse estímulos para as atividades dos alunos" (NOVA ESCOLA, apud NASCIMENTO, 2012, p. 10).

Todavia, a disparidade existente entre as classes sociais em relação ao acesso à educação refletiu na arquitetura das escolas, antes do desenvolvimento industrial, as escolas privilegiavam a formação de dirigentes, sendo assim eram instaladas em prédios imponentes e que se destacassem em seu entorno (AZEVEDO, 2002).

Com o passar dos anos, os edifícios escolares foram sendo configurados de acordo com os acontecimentos históricos do período em que eram projetados e com características dos estilos arquitetônicos referente à época de construção.

Em um breve contexto histórico pode-se dizer que durante o período de 1890 à 1920 a arquitetura dos edifícios escolares se configurava como eclética e neoclássica com ênfase para a educação tradicional. Na década de 1930, com a inclusão da modernidade, a arquitetura escolar foi marcada por alterações nos projetos, onde os ambientes passaram a ser bem demarcados e houve o surgimento de outros espaços e novas funções (MELO, 2012). De 1949 à 1954 ocorreu a repercussão das características da arquitetura moderna nas escolas. Já os anos 1960 se destacaram pela modificação das soluções construtivas, com formas poucos usuais, pelo estilo 
arquitetônico com espaços mais imponentes, maior visibilidade e menos adornos e pela continuidade na pedagogia vigente, uma certa integração entre a pedagogia clássica com a mais atual (BUFFA; PINTO, 2002).

As décadas de 1970 e 1980 foram marcadas pelo período pós-moderno, onde segundo Carvalho (2009), os projetos arquitetônicos passaram a ser padronizados e sistematizados, com a utilização de elementos pré-moldados, favorecendo uma produção econômica e rápida de edifícios.

Nos anos 1990 e 2000, o cenário político e econômico do país, com a reforma do Estado e a recessão econômica, resultou na ampliação da demanda das escolas públicas e na universalização do acesso à educação. A democratização escolar e os edifícios escolares eram utilizados para alavancar a política e economia, como sinônimo de modernidade e progresso, dessa forma, o governo visava aumentar rapidamente a quantidade de escolas públicas construindo edifícios em série, com técnicas construtivas e tipologias padronizadas, erguidos de forma rápida e com baixo custo (FERNANDES, 2015).

\section{ESTUDO DE CASO: ESCOLA ANTÔNIO MOREIRA LIMA}

Visto que a estrutura física do espaço serve como suporte no desenvolvimento da educação, a identificação da tipologia arquitetônica das unidades de ensino é de suma importância já que ao longo dos anos e da história, a estrutura física das instituições pode sofrer modificações. Neste trabalho, estudou-se a escola de ensino fundamental Antônio Moreira Lima, localizada no conjunto habitacional Ana Jacinta em Presidente Prudente - SP.

Através de analises documentais foi constado que a unidade foi instalada em 14 de fevereiro de 2002 com o nome provisório de EMEIF Ana Jacinta. Neste mesmo ano, o nome foi alterado para EMEIF Antônio Moreira Lima, sendo inaugurada apenas em junho de 2004 . Em 2006, com o mesmo nome, passou a ser EMEF, atendendo ao ensino fundamental do $1^{\circ}$ ao $5^{\circ}$ ano e oferecendo ensino integral às crianças através do programa Cidade escola.

Os anos 2000, época da construção da escola, faz parte do período caracterizado como arquitetura contemporânea, estilo produzido após o pós-modernismo. A arquitetura contemporânea é marcada por diversas influencias e abrange várias tendências, correntes e técnicas arquitetônicas, entretanto, a escola em questão não possui características que a classifique em alguma corrente especifica desse estilo.

Destaca-se que o projeto arquitetônico desta unidade claramente seguiu um padrão construtivo, com materiais e soluções arquitetônicas simples e de baixo custo. Identificou-se que muitas das características presentes no projeto seguem a padronização disponibilizada nas diretrizes do FDE - Fundação para o Desenvolvimento da Educação.

O projeto é dividido em blocos que são interligados por circulação, em sua maioria em forma de rampas e escadas, devido a topografia íngreme. Os blocos são setorizados de acordo com a função exercida pelo ambiente, sendo: um bloco composto apenas por sala de aulas e sanitários; um bloco que abriga o setor administrativo, de serviço, e o refeitório, sendo estes independentes e isolados uns dos outros; um bloco com a sala dos professores, uma quadra coberta, e a casa do zelador. Os ambientes e as circulações são articulados para manter a privacidade na realização das atividades de ensino ao mesmo tempo que possibilita o encontro de pessoas e a conexão dos espaços (Figura 1). 
Figura 1 - Setorização dos ambientes da escola

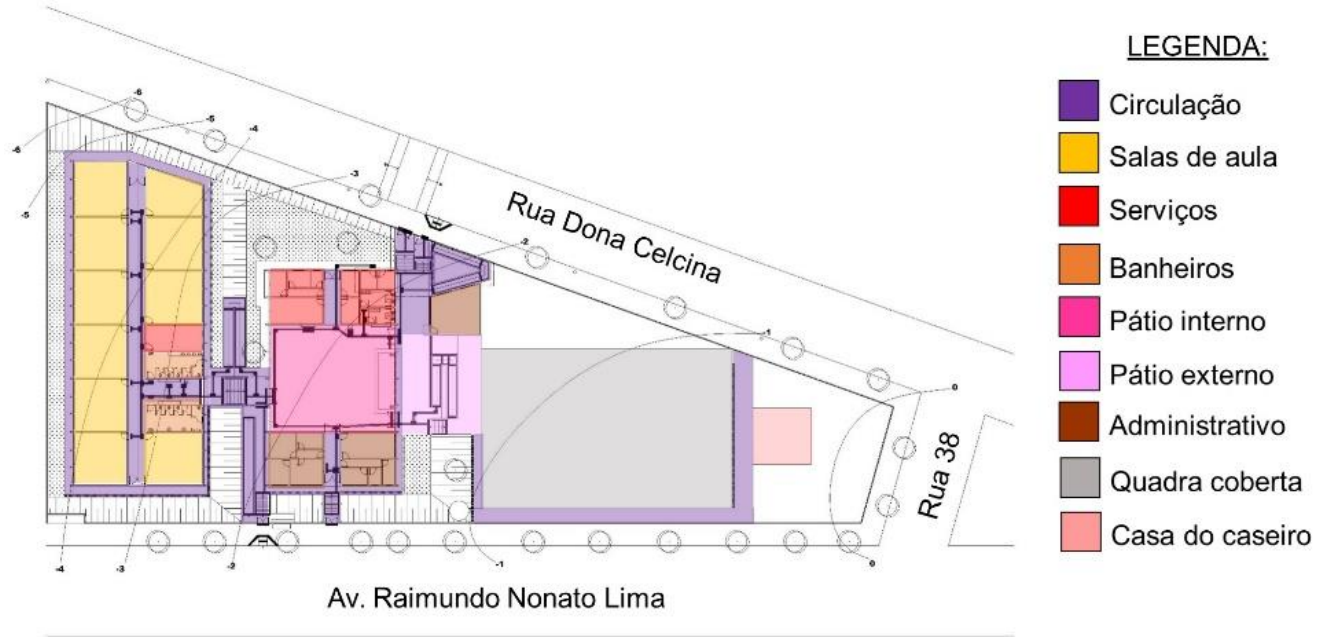

(Fonte: Autoras, 2017.)

A escola possui dois acessos distintos, um para alunos, aberto apenas nos horários de entrada e saída e um que permanece aberto ao público e possibilita o acesso ao setor administrativo. A integração do interno com o externo ocorre por meio das esquadrias em vidro e ferro que são distribuídas por toda a edificação. Na área externa há parquinho, mesas e bancos destinados ao uso recreativo.

O prédio, que em sua maio parte já era acessível desde sua construção, passou por uma reforma no ano de 2011 onde foram feitas pequenas intervenções que o tornaram completamente dotado de acessibilidade (Figura 2), onde é possível ter mobilidade sem obstáculos.

Figura 2 - Rampas que interligam os blocos da escola

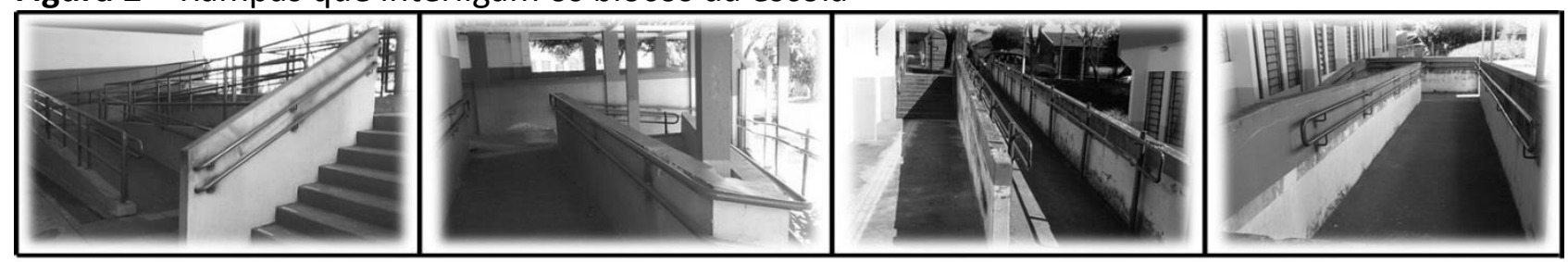

(Fonte: Autoras, 2016.)

Por fim, a edificação possui identidade de obra pública, com formas simples e cores que remetem a grande maioria das escolas do município.

\section{CONSIDERAÇÕES FINAIS}

A partir desta pesquisa foi possível constatar que as tipologias arquitetônicas das unidades de ensino, estando ou não em conformidade com o período arquitetônico, são definidas com base nas necessidades apresentadas pela sociedade da época de concepção do projeto. Assim, concluise que a escola Antônio Moreira Lima pertence ao período arquitetônico contemporâneo e faz parte do conjunto de instituições escolares que segue os padrões dispostos pelo governo para construções rápidas e econômicas com a finalidade de ampliar a oferta de novas vagas que supram a demanda da rede pública de ensino.

\section{REFERÊNCIAS BIBLIOGRÁFICAS}

AZEVEDO, G. A. N.; BASTOS, Leopoldo E.G.; BLOWER, Hélide S. O moderno já passado - o passado no moderno. In: Anais do III Seminário Projetar. 2007. 
AZEVEDO, G. A. N. Arquitetura Escolar e Educação: Um Modelo Conceitual de Abordagem Interacionista. 2002. 236 f. Tese (Doutorado em Engenharia de Produção) - Universidade Federal do Rio de Janeiro, Rio de Janeiro - RJ.

BRASIL. Constituição Federal Brasileira. 1988.

BUFFA. E, PINTO. G. A. Arquitetura e Educação: Organização do Espaço e Propostas Pedagógicas dos Grupos Escolares Paulistas, 1893/1971. 1. ed. São Carlos: EDUFSCar/INEP, 2002. Introdução, p. 17-27.

CARVALHO, I. Projeto Arquitetônico Escolar: uma proposta voltada à Educação Ambiental. 2009. 227p. Trabalho Final de Graduação (TFG) - Faculdade de Arquitetura e Urbanismo da Universidade Federal do Pará (FAU-UFPa). Pará, 2009.

DELIBERADOR, Marcella S. O processo de projeto de arquitetura escolar no Estado de São Paulo: caracterização e possibilidades de intervenção. (Dissertação de Mestrado) Campinas: UNICAMP. 2010.

FARIA Fo., Luciano Mendes de; VIDAL, Diana G. Os tempos e os espaços escolares no processo de institucionalização da escola primária no Brasil. In: Revista Brasileira de Educação. No. 14, PP.1935. 2000. Disponível em: http://www.scielo.br/pdf/rbedu/n14/n14a03.pdf. Acesso em 06 fev. 2015.

FERNANDES, F.M. Expansão do ensino fundamental brasileiro e suas implicações na produção arquitetônica escolar paulista nas décadas finais do século XX. (Dissertação de Mestrado) Presidente Prudente: UNOESTE, 2015.

KOWALTOWSKI, Doris C. C. K., Arquitetura escolar o projeto do ambiente de ensino. São Paulo: Oficina de Textos, 2011

MELO, L. G. Arquitetura escolar e suas relações com a aprendizagem. 2012. $34 \mathrm{f}$. Trabalho de Conclusão de Curso (Graduação em Pedagogia) - Universidade do Estado do Rio de Janeiro, São Gonçalo - RJ.

NASCIMENTO, M. F. P. Arquitetura para a educação: A contribuição do espaço para a formação do estudante. 2012. 154 f. Dissertação (Mestrado em História e Fundamentos da Arquitetura e do Urbanismo) - Universidade de São Paulo, São Paulo - SP.

SAVIANI et al. O legado educacional do século XX no Brasil. 2a. Ed. Campinas: Autores Associados, 2006.

VIÑAO, Frago A. História de laeducación e historia cultural: posibilidades, problemas, cuestiones. In: Revista Brasileira de Educação. No. 0, PP.63-82. 1995. Disponível em: http://educa.fcc.org.br/scielo.php?pid=S1413-24781995000100005\&script=sci_arttext. Acesso em: 05 fev. 2015. 